\title{
Recent lactate findings: is repeated serum lactate testing necessary in septic shock patients?
}

\author{
Moo Suk Park \\ Division of Pulmonology, Department of Internal Medicine, Severance Hospital, Institute of Chest Diseases, Yonsei University College of Medicine, Seoul, \\ Korea
}

Within the broader category of sepsis, septic shock is a distinct clinical entity characterized by circulatory and metabolic (i.e., cellular) dysfunction; its mortality rate (more than $40 \%$ ) is higher than that of either hyperlactatemia alone (less than $30 \%$ mortality) or patients treated with vasopressors alone (30\% mortality) [1]. The clinical criteria of septic shock are a serum lactate level $>2 \mathrm{mmol} / \mathrm{L}(18 \mathrm{mg} / \mathrm{dl})$ continuing in spite of adequate volume resuscitation and persistent hypotension for which vasopressors are required to maintain a mean arterial pressure $\geq 65 \mathrm{mmHg}[1]$.

Shock is presented by hyperlactatemia and abnormal tissue hypoperfusion [2]. Early resuscitation is an essential aspect of treating septic shock [3]. Serum lactate can serve as a surrogate marker of tissue perfusion, even though it is not a direct indicator of perfusion [4], because elevated serum lactate levels are associated with hypoxia in the tissues and higher rates of aerobic glycolysis resulting from abnormally high beta-adrenergic stimulation or other causes; as such, hyperlactatemia is associated with a poor prognosis [5]. Lactate-guided resuscitation has been shown to lead to a significantly lower risk of mortality, with a relative risk of 0.67 (95\% confidence interval, 0.53 to 0.84 ) [6-9]. Two meta-analyses enrolling 647 patients demonstrated that implementing a strategy focusing on early lactate clearance led to lower rates of in-hospital mortality than either a strategy focusing on $\mathrm{ScvO}_{2}$ normalization or usual care $[10,11]$.

As increased serum lactate levels, lactate kinetics are associated with mortality [12], the Surviving Sepsis Campaign has suggested that hemodynamic resuscitation should be guided by repeated assessments of serum lactate levels at intervals of 2 to 4 hours until lactate levels normalize [13]. However, sometimes other causes rather than tissue hypoperfusion, may persistently increase serum lactate levels [14], lactate kinetics may gradually return to normal even in survivors [12,15], and it may not be possible to measure lactate levels in all circumstances. Thus, the identification of alternative targets for resuscitation is a major desideratum of research in the field of sepsis [16].

In pediatric patients with septic shock, the lactate area score, which is defined as the area under the curve of measured lactate levels, was established to be an independent factor that predicted mortality [17]. However, few studies have investigated the role of the lactate area score in predicting the prognosis of septic shock $[17,18]$ and pediatric or geriatric patients were enrolled in intensive care unit (ICU). In a single tertiary medical center, 362 adult septic shock patients were enrolled in the emergency department. The authors found that serial

\section{Editorial}

Received: May 12, 2019

Accepted: May 13, 2019

Corresponding author

Moo Suk Park

Division of Pulmonology, Department of Internal Medicine, Severance Hospital, Institute of Chest Diseases, Yonsei University College of Medicine, 50-1 Yonsei-ro, Seodaemun-gu, Seoul 03722, Korea

Tel: +82-2-2228-1955

Fax: +82-2-393-6884

E-mail:pms70@yuhs.ac

Copyright $(2019$ The Korean Society of Critical Care Medicine

This is an Open Access article distributed under the terms of Creative Attributions Non-Commercial License (http:/I creativecommons.org/li-censes/by-nc/4.0/) which permits unrestricted noncommercial use, distribution, and reproduction in any medium, provided the original work is properly cited. 
lactate measurements with five times within 12 hours and lactate area score were independently associated with 28-day mortality. Unfortunately, the lactate area score showed a lower odds ratio than had been reported in previous studies or that of the SOFA score for predicting mortality [19].

Increased serum lactate level and lactate kinetics are wellknown prognostic factors for mortality in patients with septic shock. However, it remains controversial how many serum lactate level checks should be performed and at what time intervals for prediction of mortality in septic shock patients. To reach firmer conclusions on these issues, it will be necessary to conduct prospective multicenter interventional studies in the future.

Recently, ANDROMEDA-SHOCK trial was reported [20]. Randomized 424 adult patients with septic shock were included at 28 ICUs in five countries between March 2017 and March 2018. A protocolized resuscitation with capillary refill time (CRT; to less than 3 seconds, $n=212$ ) guided or lactate guided (aiming to reduce lactate levels by more than $20 \%$ each 2 hours, $\mathrm{n}=212$ ) was used during initial 8-hour period. Both resuscitation strategy failed to decrease all-cause mortality at 28 days $(\mathrm{P}=0.06)$, but showed clinically meaningful results. A CRT targeting resuscitation was associated with lower Sequential Organ Failure Assessment (SOFA) score at 72 hours ( $\mathrm{P}=0.045)$. A lactate-guided resuscitation group received an excess of 400 $\mathrm{mL}$ of crystalloid over the 8-hour period as compared to the CRT group [20].

Gattinoni L et al. [21] showed that post-hoc analysis of baseline variables in a multicenter trial, named ALBumin Italian Outcome Sepsis (ALBIOS) study, enrolled 1,741 septic patients. A lactate concentration and $\mathrm{ScvO}_{2}$ were divided by sextiles. Only $35 \%$ patients among them, $\mathrm{ScvO}_{2}$ was lower than $70 \%$. The highest lactate levels, frequency of organ dysfunction, and mortality rate were observed in the first and sixth sextiles of $\mathrm{ScvO}_{2}$. Acidemia only showed an association with lactate levels in patients with renal dysfunction (creatinine $>2 \mathrm{mg}$ / $\mathrm{dl}$ ), which was detected by negative values of alactic base excess. They concluded that increased lactate level is strongly associated with severity of sepsis. The current resuscitation strategy could be modified according to the origin of hyperlactatemia because major cause is an impairment of tissue oxygen utilization rather than that of oxygen transport [21].

\section{CONFLICT OF INTEREST}

No potential conflict of interest relevant to this article was reported.

\section{ORCID}

Moo Suk Park https://orcid.org/0000-0003-0820-7615

\section{REFERENCES}

1. Singer M, Deutschman CS, Seymour CW, Shankar-Hari M, Annane D, Bauer M, et al. The Third International Consensus Definitions for Sepsis and Septic Shock (Sepsis-3). JAMA 2016; 315:801-10

2. Cecconi M, De Backer D, Antonelli M, Beale R, Bakker J, Hofer $\mathrm{C}$, et al. Consensus on circulatory shock and hemodynamic monitoring. Task force of the European Society of Intensive Care Medicine. Intensive Care Med 2014;40:1795-815.

3. Rhodes A, Evans LE, Alhazzani W, Levy MM, Antonelli M, Ferrer R, et al. Surviving Sepsis Campaign: International Guidelines for Management of Sepsis and Septic Shock: 2016. Crit Care Med 2017;45:486-552.

4. Levy B. Lactate and shock state: the metabolic view. Curr Opin Crit Care 2006;12:315-21.

5. Casserly B, Phillips GS, Schorr C, Dellinger RP, Townsend SR, Osborn TM, et al. Lactate measurements in sepsis-induced tissue hypoperfusion: results from the Surviving Sepsis Campaign database. Crit Care Med 2015;43:567-73.

6. Jansen TC, van Bommel J, Schoonderbeek FJ, Sleeswijk Visser SJ, van der Klooster JM, Lima AP, et al. Early lactate-guided therapy in intensive care unit patients: a multicenter, openlabel, randomized controlled trial. Am J Respir Crit Care Med 2010;182:752-61.

7. Jones AE, Shapiro NI, Trzeciak S, Arnold RC, Claremont HA, Kline JA, et al. Lactate clearance vs central venous oxygen saturation as goals of early sepsis therapy: a randomized clinical trial. JAMA 2010;303:739-46.

8. Ryoo SM, Lee J, Lee YS, Lee JH, Lim KS, Huh JW, et al. Lactate level versus lactate clearance for predicting mortality in patients with septic shock defined by sepsis-3. Crit Care Med 2018;46:e489-95.

9. Ryoo SM, Ahn R, Lee J, Sohn CH, Seo DW, Huh JW, et al. Timing of repeated lactate measurement in patients with septic shock at the emergency department. Am J Med Sci 2018;356: 97-102.

10. Gu WJ, Zhang Z, Bakker J. Early lactate clearance-guided therapy in patients with sepsis: a meta-analysis with trial sequential analysis of randomized controlled trials. Intensive Care Med 2015;41:1862-3.

11. Simpson SQ, Gaines M, Hussein Y, Badgett RG. Early goal-directed therapy for severe sepsis and septic shock: A living sys- 
tematic review. J Crit Care 2016;36:43-48.

12. Vincent JL, Quintairos E Silva A, Couto L Jr, Taccone FS. The value of blood lactate kinetics in critically ill patients: a systematic review. Crit Care 2016;20:257.

13. Levy MM, Evans LE, Rhodes A. The surviving sepsis campaign bundle: 2018 Update. Crit Care Med 2018;46:997-1000.

14. Garcia-Alvarez M, Marik P, Bellomo R. Sepsis-associated hyperlactatemia. Crit Care 2014;18:503.

15. Hernandez G, Luengo C, Bruhn A, Kattan E, Friedman G, Ospina-Tascon GA, et al. When to stop septic shock resuscitation: clues from a dynamic perfusion monitoring. Ann Intensive Care 2014;4:30.

16. Coopersmith CM, De Backer D, Deutschman CS, Ferrer R, Lat I, Machado FR, et al. Surviving sepsis campaign: research priorities for sepsis and septic shock. Crit Care Med 2018;46:133456.

17. Wang H, Li Z, Yin M, Chen XM, Ding SF, Li C, et al. Combination of Acute Physiology and Chronic Health Evaluation II score, early lactate area, and N-terminal prohormone of brain natriuretic peptide levels as a predictor of mortality in geriat- ric patients with septic shock. J Crit Care 2015;30:304-9.

18. Kim YA, Ha EJ, Jhang WK, Park SJ. Early blood lactate area as a prognostic marker in pediatric septic shock. Intensive Care Med 2013;39:1818-23.

19. Yu G, Yoo SJ, Lee SH, Kim JS, Jung S, Kim YJ, et al. Utility of the early lactate area score as a prognostic marker for septic shock patients in the emergency department. Acute Crit Care 2019; 34:126-32.

20. Hernández G, Ospina-Tascón GA, Damiani LP, Estenssoro E, Dubin A, Hurtado J, et al. Effect of a resuscitation strategy targeting peripheral perfusion status vs serum lactate levels on 28-day mortality among patients with septic shock: The ANDROMEDA-SHOCK Randomized Clinical Trial. JAMA 2019; 321:654-64.

21. Gattinoni L, Vasques F, Camporota L, Meessen J, Romitti F, Pasticci I, et al. Understanding lactatemia in human sepsis: potential impact for early management. Am J Respir Crit Care Med 2019 Apr 15 [Epub]. https://doi.org/10.1164/rccm.2018122342OC. 